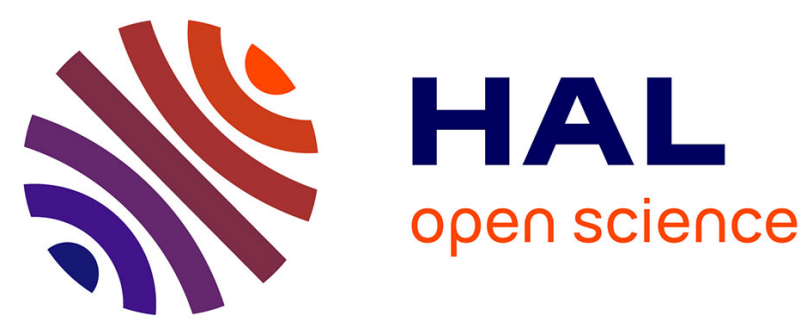

\title{
BaFe12O19 SMALL PARTICLES : FORMATION. PARTICLE SIZE AND MAGNETIC PROPERTIES
}

\author{
R. Ardiaca, M. Medarde, X. Obradors, Maxime Vallet, M. Pernet, J.
} Rodríguez, J. Fontcuberta

\section{To cite this version:}

R. Ardiaca, M. Medarde, X. Obradors, Maxime Vallet, M. Pernet, et al.. BaFe12O19 SMALL PARTICLES : FORMATION. PARTICLE SIZE AND MAGNETIC PROPERTIES. Journal de Physique Colloques, 1988, 49 (C8), pp.C8-1849-C8-1850. 10.1051/jphyscol:19888846 . jpa-00229105

\section{HAL Id: jpa-00229105 https://hal.science/jpa-00229105}

Submitted on 1 Jan 1988

HAL is a multi-disciplinary open access archive for the deposit and dissemination of scientific research documents, whether they are published or not. The documents may come from teaching and research institutions in France or abroad, or from public or private research centers.
L'archive ouverte pluridisciplinaire HAL, est destinée au dépôt et à la diffusion de documents scientifiques de niveau recherche, publiés ou non, émanant des établissements d'enseignement et de recherche français ou étrangers, des laboratoires publics ou privés. 


\section{BaFe $_{12} \mathrm{O}_{19}$ SMALL PARTICLES: FORMATION. PARTICLE SIZE AND MAGNETIC PROPERTIES}

R. Ardiaca $\left({ }^{1}\right)$, M. Medarde $\left({ }^{2}\right)$, X. Obradors $\left({ }^{1}\right)$, M. Vallet $\left({ }^{3}\right)$, M. Pernet $\left({ }^{4}\right)$, J. Rodríguez $\left({ }^{2}\right)$ and J. Fontcuberta $\left({ }^{1}\right)$

(1) Dep. Física Fonamental. Universitat de Barcelona, Diagonal 647, 08028 Barcelona, Spain

(2) T.L.L., 156X, 38042 Grenoble, Francia

(3) Fac. Quźmica. Universidad Complutense, 28040 Madrid, Spain

( $\left.{ }^{4}\right)$ Lab. Cristallographie, CNRS 166X, Grenoble, Francia

Abstract. - Small particles of $\mathrm{BaFe}_{12} \mathrm{O}_{19}$ are prepared at low temperature by a liquid mix technique. By using $\mathrm{X}$-ray diffraction, Mössbauer, and magnetic measurements we show that this method allows an easy control of the size and shape $(400 \AA-3000 \AA)$ of the particles, which display essentially bulk magnetic properties.

Hexagonal-ferrite small particle are being widely considered as interesting materials for high density magnetic recording media. A great effort is then being performed on preparing materials with proper size, crystal size homogeneity and controlled magnetic properties. In recent works [1] it has been shown that the liquid mix technique is an interesting synthesis method for this purpose. It seems then necessary to study the relationship among thermal treatments, phase formation, crystal size and magnetic properties. In this work we extend previous reports dealing with the relationship among all these items.

Samples of $\mathrm{BaFe}_{12} \mathrm{O}_{19}$ composition where prepared by the liquid mix technique. Detailed procedure can be found elsewhere [1]. Here we only mention that the investigated samples where prepared with different thermal treatments, from $T=450{ }^{\circ} \mathrm{C}$ to $T=1150{ }^{\circ} \mathrm{C}$ for different periods of time $(t)$. X-ray diffraction analysis was carried out by using a Siemens $2 \theta$-diffractometer and $\mathrm{Cu}-\mathrm{K} \alpha_{1}$ radiation. The Rietveld profile analysis method was used, both to refine structural parameteres and to deduce the relative concentration of the differents phases when present.

Electron microscopy photographs show that particles have an hexagonal platelet-like shape and allows a measure of the averaged size perpendicular to hexagonal axis but does not provide any estimation of the highness along this axis. The broadening of the X-ray diffraction peaks $(\mathbf{H})$ permits a measure of the particle size in a direction perpendicular to $\mathbf{H}$. Thus from $\mathrm{X}$-ray diffraction a reasonable measure of the averaged particle size along some directions and the shape of the particles can be obtained. The reflections (006) (104) (110) (008) (112) (107) (114) (203) (205), (206) and (220) have ben used to evaluate the particle size and shape according to the method of Cox [2]. Mössbauer spectroscopy was used to perform phases analysis as well as to characterize the hyperfine parameters of these phases, which usually are in a small particle form.
A SQUID magnetometer was used to obtain hysteresis curves.

X-ray (XRD) and Mössbauer spectroscopy (MS) analysis lead to the following conclusions. (1) The spinel phase $\gamma-\mathrm{Fe}_{2} \mathrm{O}_{3}$ is formed at $T>150^{\circ} \mathrm{C}$. (2) At $T \approx 450^{\circ} \mathrm{C}$ small particles of the magnetoplumbite M-phase exist as can be observed by MS but not by $\mathrm{XRD}$. At this temperature $\mathrm{BaFe}_{2} \mathrm{O}_{4}$ oxide is detected by XRD but it is not observable by MS at least when the reported hyperfine parameters [3] for $\mathrm{BaFe}_{2} \mathrm{O}_{4}$ are considered. As shown in figure 1 the severe overlapping of the spectra may cause the failure to observe $\mathrm{BaFe}_{2} \mathrm{O}_{4}$ by MS. (3) When samples are beated again at $700{ }^{\circ} \mathrm{C}$ for $t=2 \mathrm{~h}$ the concentration of the M-phase increases further at expense of the $\mathrm{BaFe}_{2} \mathrm{O}_{4}$ oxide.

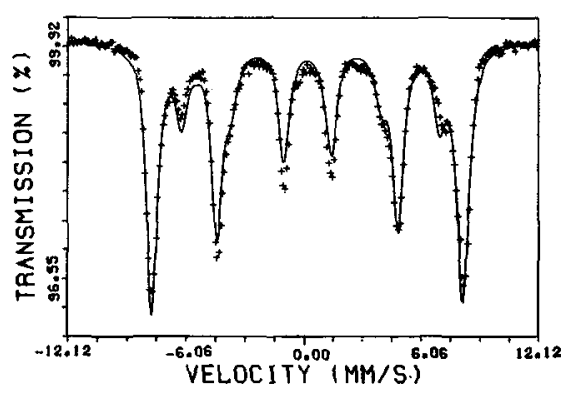

Fig. 1. - Room-temperature Mössbauer spectra of sample prepared at $T=600^{\circ} \mathrm{C}, t=1 \mathrm{~h}$.

The concentration of the spinel phase [S], as observed by MS, decreases when increasing the annealing temperature. At $T=450{ }^{\circ} \mathrm{C},[S] /[M] \approx 2$, but at $T=750^{\circ} \mathrm{C},[S] /[M] \approx 0.07$ where $[M]$ denotes the relative concentration of the M-phase. (4) At this tem- 
perature $\left(T<800^{\circ} \mathrm{C}\right)$ the particle size is not very sensitive to the annealing time " $t$ " . By using the Cox linebroadening analysis we got, (for $T=750^{\circ} \mathrm{C}, t=1 \mathrm{~h}$ ), $D \approx 695 \AA, H \approx 508 \AA$ but $D \approx 826 \AA, H \approx 517 \AA$, for $T=750{ }^{\circ} \mathrm{C} t=6 \mathrm{~h}$. (5) When the sample is heated at higher temperature, say $T>800^{\circ} \mathrm{C}$, no $\mathrm{BaFe}_{2} \mathrm{O}_{4}$ is observed by XRD. $\alpha-\mathrm{Fe}_{2} \mathrm{O}_{3}$ oxide is formed by oxidation of the preexisting spinel phase, but its concentration never exceeds $12 \%$. The particles size increases rapidly for longer annealing times. At $T=1000^{\circ} \mathrm{C}$, $t=1 \mathrm{~h}, D \approx 2320 \AA, H \approx 1133 \AA$, but at this temperature the rate of growing is about three times faster than at $700{ }^{\circ} \mathrm{C}$. (6) The concentration of $\alpha-\mathrm{Fe}_{2} \mathrm{O}_{3}$ decrease when samples are heated at $T>900^{\circ} \mathrm{C}$ but it is still present $(<3 \%)$ for $T \approx 1000^{\circ} \mathrm{C}$. From the magnetic point of view the analysis of the samples has revealed the following prominent features. (7) The saturation magnetization $\left(M_{s}\right)$ increases when the annealing temperature $T$ or the annealing time $t$ increases, approaching to the expected $100 \mathrm{emu} / \mathrm{gr}$ for $T>1000{ }^{\circ} \mathrm{C}$. (8) The coercitive magnetic field as deduced from the hysteresis loops, versus the mean size of the particles (D) shows a maximum around 4 $5 \mathrm{KOe}$ for $D \approx 1000 \AA$, decreasing above and below this size. (9) The superimposed susceptibility at high fields decreases when $T$ and/or $t$ increases. (10) Mössbauer spectra have revealed that the hyperine magnetic fields for the M-phase increases slighly when samples are annealed at higher $T$ or longer $t$, thus pointing to bulk values. (11) Even for the the samples prepared at low temperatures when the paricle size is smaller $(<400 \AA)$ the Mössbauer spectra does not reveal any superparamagnetic effect. A lower limit for particle size could be obtained by using the Neel law. When the appropriate anisotropy constant is used $\left(\approx 4.5 \times 10^{6} \mathrm{erg} \mathrm{cm}^{-3}\right.$ for bulk material $)$ a particle size not larger than $100 \AA$ is found.

From XRD and Mössbauer data we may conclude that the hexaferrite is formed according to the following scheme. At $T<150{ }^{\circ} \mathrm{C} \gamma-\mathrm{Fe}_{2} \mathrm{O}_{3}$ and $\mathrm{BaFe}_{2} \mathrm{O}_{4}$ oxides are formed. At higher $T$ the solid state reaction between both oxides leads to the M-phase forma- tion. The existence of a small amount of $\alpha-\mathrm{Fe}_{2} \mathrm{O}_{3}$ reveals that some $\mathrm{Ba}$ was preexisting in a different form $(\mathrm{BaO}, \ldots)$, both oxides reacting at high temperature, and leading to a lowering of the $\alpha-\mathrm{Fe}_{2} \mathrm{O}_{3}$ phase as observed. It is to be remarked that at $750^{\circ} \mathrm{C},[M] \approx 90 \%$ and the particle size can be easily controled.

The magnetic data can be interpreted as follows. The dependence of $M_{s}$ on particle size reveals spinreduction effects at the surface of the grains [4] which also accounts for the existence of the superimposed magnetic susceptibility. The same argument holds for Mössbauer data. It is worth to comment the non observance of any sizeable relaxation effect, thus showing that the axial magnetic anisotropy is strong enough to avoid spin relaxation (at $300 \mathrm{~K}$ ) in the Mössbauer time scale.

On the other hand, measured coercitive magnetic fields ranging from 2-5 KOe are excedingly high for magnetic recording pourpose, and some cationic substitution is in order.

Summarizing, we can conclude that liquid mix technique allows low-temperature $M$-phase synthesis with controled particle size and shape. The magnetic properties of this particles are essentially coincident with those of bulk materials except, perhaps, the effects associated to surface spin-reduction.

[1] Vallet, M., Rodríguez, R., Obradors, X., Isalgué, A., Rodríguez, J. and Pernet, M., J. Phys. France 46 (1985) C6-335;

Ardiaca, R., Ramos, R., Isalgué, A., Rodríguez, J., Obradors, X., Pernet, M. and Vallet, M., IEEE Trans. Magn. MAG 23 (1987) 22.

[2] Thomtson, P., Cox, D. E., Hastings, J. B., J. Appl. Cryst. 20 (1987) 79.

[3] Do-Dinh, C., Bertaut, E. F. and Chappert J., $J$. Phys. France 30 (1969) 566.

[4] Morrish, A. H. and Kaneda, K., J. Magn. Magn. Mater. 35 (1983) 105. 